\title{
PELATIHAN STRUKTUR MAINTENANCE DAN PEREMAJAAN PADA LABORATORIUM KOMPUTER SMPN 101 JAKARTA BARAT
}

\author{
Rayung Wulan 1), Suranto Saputra ${ }^{2)}$, Abdul mufti ${ }^{3)}$, \\ Program Studi Informatika, Fakultas Teknik dan Ilmu Komputer \\ Universitas Indraprasta PGRI
}

\begin{abstract}
Abstrak
Maintenance pada dasarnya serangkaian aktivitas perawatan untuk mencegah kerusakan yang fatal dalam sistem komputer. Pentingnya maintenance pada perangkat komputer sangat diperlukan saat ini melihat perkembangan arus teknologi informasi yang terus meningkat. Dalam memahami struktur maintenance dan peremajaan dibutuhkan pelatihan tentang tata cara memperbaiki serta perawatan apa yang dibutuhkan di laboratorium tersebut agar tidak terjadi kerusakan yang fatal. Tujuan pelatihan ini mencegah kerusakan dan memahami peramajaan baik software dan hardware yang ada dilaboratorium tersebut. Maintenace dan peremajaan bisa dijadwalkan secara berkala dilihat dari intensitas pemakaian sehari hari, jika intensitasnya padat maka dilakukan dalam satu bulan sekali agar kinerja perangkat hardware dan softwarenya berjalan dengan baik. Buku manual yang akan dibuat berisi tentang prosedur \& langkah langkah maintenance dan peremajaan secara menyeluruh baik software dan hardware yang ada si laboratorium tersebut agar petugas laboratorium komputer memahami struktur maintenance dan peremajaan di laboratorium SMPN 101 Jakarta Barat.
\end{abstract}

Kata kunci : Struktur Maintenace, Peremajaan, Laboratorium Komputer

\begin{abstract}
Basicly, maintenance is a series of treatment activity to prevent fatal damage in computer system. The importance of maintenance on computer equipment is very needed nowadays seeing the development of information technology flow that increase continually. Understanding the structure maintenance and rejuvenation are needed the training about how to fix and what maintenance are needed in the laboratory so that fatal damage does not occur. The purpose of the training is to prevent the damage and to implementing understand rejuvenation either software or hardware in the laboratory. Maintenance and rejuvenation could be scheduled regularly in terms of the intensity of daily use. If the intensity is busy, it will be held once in a month so that hardware and software equipment running well. The manual book that will be made contains procedures and the steps of maintenance and rejuvenation overall either software or hardware in the computer laboratory so that computer laboratory assistant understands maintenance structure and rejuvenation at the laboratory of SMPN 101 West Jakarta.
\end{abstract}

Key words: Maintenance structure, rejuvenation. Computer laboratory of SMPN 101

Correspondence author: Rayung Wulan, utha2578@gmail.com, Jakarta, Indonesia

This work is licensed under a $C C-B Y-N C$

\section{PENDAHULUAN}

Perlunya maintenance pada perangkat komputer yang digunakan secara berkala bertujuan untuk menjaga performa dari perangkat dan agar perangkat komputer tidak 
mengalami kerusakan sebelum waktu masa garansi habis. Maintenance merupakan sebuah pekerjaan yang dilakukan secara berurutan untuk menjaga atau memperbaiki fasilitas yang ada sehingga sesuai dengan standar (sesuai dengan standar fungsional dan kualitas).

Laboratorium komputer di SMPN 101 terdiri dari dua ruang laboratorium yang masing masing laboratorium terdiri dari 38 komputer jumlah komputer yang efektif untuk praktikum 72 unit komputer cadangan sebanyak 4 buah. Terdapat Server dimasing masing ruang laboratorium komputer, untuk memantau masing masing komputer yang digunakan siswa/i dalam menerima pelajaran praktikum.

Pada Perangkat komputer ada dua hal yang dapat kita maintenance yaitu : Maintenance Software dan Maintenance Hardware. Maintenance software dapat dilakukan dengan beberapa cara di antarannya :

1. Maintenance disk (disk defragmenter/disk cleaner)

Disk defragment diperlukan agar sistem dapat mengatur kembali file-file di dalam komputer secara rapi. Sedangkan disk cleaner berfungsi untuk membersihkan sampah-sampah dari sisa kinerja komputer.

2. Melakukan update software dan operating system

Update software dan operating system dilakukan secara berkala agar menjaga performa dari software yang digunakan sehari-hari.

Sedangkan Maintenance hardware dapat dilakukan dengan beberapa cara antara lain:

1. Membersihkan perangkat komputer dari kotoran

Debu yang menempel diperangkat seperti pada monitor, keyboard, mouse dan bagian dalam CPU perlu dibersihkan untuk mencegah adanya kerusakan komponen atau mengurangi kinerja komponen saat perangkat komputer digunakan.

2. Menambahkan thermal pasta pada prosesor komputer

Thermal pasta digunakan untuk meningkatkan konduktivitas termal antara dua permukaan dengan mengisi celah-celah mikroskopis. Apabila pasta pendingin prosesor (Thermal Pasta) sudah kering dapat menyebabkan suhu khususnya pada prosesor menjadi panas.

3. Merapihkan kabel

Kabel-kabel yang terpasang harus dirapihkan dengan baik untuk menghindari terjadinya konsleting pada arus listrik.

4. Melakukan pengecekan kondisi

Pengecekan kondisi dilakukan untuk mengetahui apakah perangkat sudah berfungsi sebagaimana mestinya seperti fungsi click pada mouse dan scroll mouse yang masih berfungsi dengan baik, tombol keyboard yang dapat digunakan dengan baik.

Peremajaan adalah kegiatan untuk memelihara atau menjaga fasilitas/peralatan pabrik dan mengadakan perbaikan atau penyesuaian/penggantian yang diperlukan supaya terdapat suatu keadaan operasi produksi yang memuaskan sesuai dengan apa yang direncanakan.

Maintenance adalah segala kegiatan yang di dalamnya adalah untuk menjaga sistem peralatan agar bekerja dengan baik (Jay Heizer dan Barry Render, 2001). Perlunya maintenance pada perangkat komputer yang digunakan secara berkala bertujuan untuk menjaga performa dari perangkat dan agar perangkat komputer tidak mengalami 
kerusakan sebelum waktu masa garansi habis. Menurut (M.S Sehwarat dan J.S Narang, 2001) mengemukakan Pada Perangkat komputer ada dua hal yang dapat kita maintenance yaitu : Maintenance Software dan Maintenance Hardware, keduanya saling berhubungan dengan komponen lainnya.

\section{Jenis - Jenis Pemeliharaan (Maintenance)}

1. Planned Maintenance (Perawatan yang Terencana)

Planned maintenance merupakan suatu kegiatan perawatan yang dilaksanakan berdasarkan perencanaan terlebih dahulu. Pemeliharaan perencanaan ini mengacu pada rangkaian proses produksi.

Planned maintenance ini terdiri atas :

Preventive Maintenance (Perawatan Pencegahan) ialah pemeliharaan yang dilaksanakan dalam periode waktu yang tetap atau dengan kriteria tertentu pada berbagai tahap proses produksi. Tujuannya agar produk yang dihasilkan sesuai dengan rencana, baik mutu, biaya, maupun ketepatan waktunya.

\section{Unplanned Maintenance (Perawatan Tidak Terencana)}

Unplanned maintenance ialah sebuah pemeliharaan yang dilakukan karena adanya indikasi atau petunjuk bahwa adanya tahap kegiatan proses produksi yang tiba-tiba memberikan hasil yang tidak layak.

Selanjutnya perlu dilakukan kegiatan pemeliharaan atas koMputer secara tidak berencana.

Unplanned maintenance ini terdiri dari :

a. Emergency Maintenance (Perawatan Darurat) ialah kegiatan perawatan komputer yang memerlukan penanggulangan yang bersifat darurat agar tidak menimbulkan akibat yang lebih parah.

b. Breakdown Maintenance (Perawatan Kerusakan) yaitu pemeliharaan yang bersifat perbaikan yang terjadi ketika peralatan mengalami kegagalan dan menuntut perbaikan darurat atau berdasarkan prioritas.

c. Corrective Maintenance (Perawatan Penangkal) seperti antivirus, utility merupakan pemeliharaan yang dilaksanakan karena adanya hasil produk (setengah jadi maupun barang jadi) tidak sesuai dengan rencana, biaya, maupun ketepatan waktunya. Misalnya: Adanya ancama malware atau sejenisnya

d. Scheduled Maintenance (Perawatan Terjadwal) yaitu perawatan yang bertujuan mencegah terjadinya kerusakan dan perawatannya dilakukan secara periodik dalam rentang waktu tertentu. Rentang waktu perawatan ditentukan berdasarkan intensitas pemakaian laboratorium computer.

e. Predictive Maintenance (Perawatan Prediktif) yakni strategi perawatan di mana pelaksanaanya didasarkan kondisi laboratorium komputer tersebut. Perawatan prediktif disebut juga perawatan berdasarkan kondisi (condition based maintenance) atau juga disebut monitoring kondisi laboratorium komputer, yang artinya sebagai penentuan kondisi laboratorium komputer dengan cara memeriksa masing masing komputer secara rutin, sehingga dapat diketahui keandalan computer tersebut serta proses belajar mengajar terjamin.

Maintenance laboratorium dan peremajaan merupakan salah satu usaha dalam rangka mengelola laboratorium. Suatu laboratorium dapat dikatakan sesuai dengan 
perkembangan Teknologi mana kala kapan pun siswa/i gunakan saat mata pelajaran di laboratorium computer dengan baik, dimana penggunaaan tersebut sangat ditentukan oleh beberapa faktor yang saling berkaitan satu dengan yang lainnya. Beberapa komponen laboratorium yang saling terhubung dan berkaitan antara satu dengan yang lainnya, dengan pemakaian yang terus menurus tanpa maintenance yang baik belum tentu dapat berfungsi dengan baik, jika tidak didukung oleh adanya peremajaan yang sesuai dengan perkembangan saat ini. Maintenace dan peremajaan pada laboratorium komputer di SMPN 101 merupakan bagian yang terpenting dan tidak dapat dipisahkan dari kegiatan laboratorium sehari-hari. Pengelolaan laboratorium dapat berjalan dengan lebih efektif dan efisien dalam pelaksanaannya harus diimbangi oleh peremajaan dalam setiap perkembangannya. Erat kaitannya dengan peremajaan komponen laboratorium, perawatan dimaksudkan sebagai usahapreventif atau pencegahan agar peralatan tidak rusak atau tetapterjaga dalam kondisi baik, siap beroperasi. Disamping ituperawatan juga dimaksudkan sebagai upaya untuk menyetel ataumemperbaiki kembali peralatan laboratorium yang sudah terlanjur rusak atau kurang layak sehingga siap digunakan untuk kegiatan praktikum (Permanasari, 2006)

\section{METODOLOGI PELAKSANAAN}

Metode penelitian yang tim abdimas gunakan dalam pelaksanaan pengabdian masyarakat ini antara lain dengan menggunakan Metode kualitiatif, melalui langkah langkah sebagai berikut :

1. Studi lapangan Laboratorium SMPN 101 Jakarta barat

Studi lapangan langsung ke Laboratorium SMPN 101 Jakarta barat, Tim abdimas kami mendapat sambutan hangat dari pihak SMPN 101 Jakarta barat diwakilkan langsung oleh Guru petugas dan guru bidang studi mata pelajaran laboratorium komputer. Kami tim abdimas dipersilahkan untuk mengamati Laboratorium di SMPN 101 Jakarta barat. Pertama yang kami lakukan melihat instalasi dan mengamati masing masing komputer yang ada dan pengecekan standar yaitu instalasi jaringan antar komputer di Laboratorium tersebut.

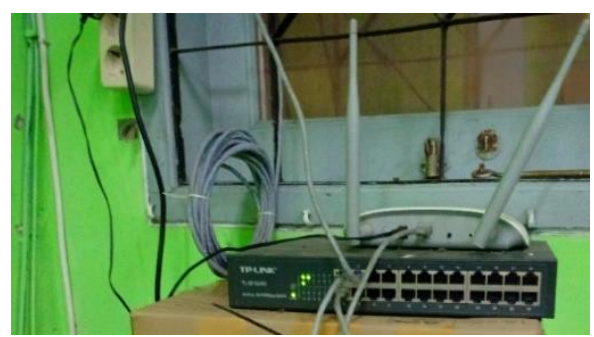

Gambar 1 Pengecekan Instalasi Jaringan

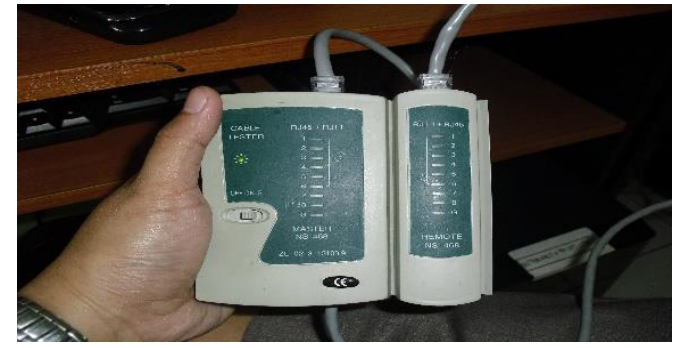

Gambar 2 Tester kabel masing masing Komputer

2. Pelatihan dan Implementasi

Setelah dilakukan pengecekan dan melihat satu persatu secara umum dilakukan pelatihan untuk guru guru di SMPN 101, pemaparan pengertian struktur maintenance dan peremajaan komputer untuk guru guru dilakukan dengan metode antara lain membagikan modul, slide pemaparan dan diskusi tanya jawab. 


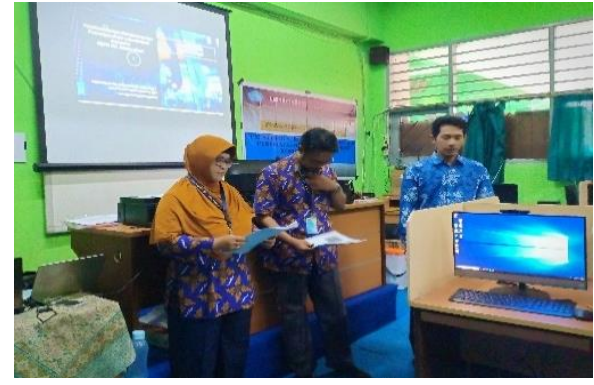

Gambar 3 Pemaparan Struktur Maintenace

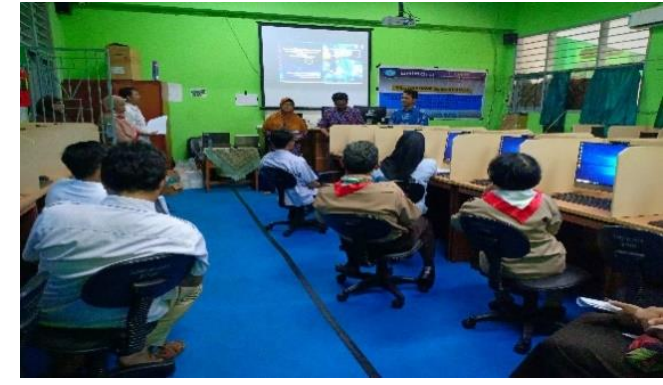

Gambar 4 Implementasi Peremajaan Komputer

\section{HASIL DAN PEMBAHASAN}

Struktur maintenance dan peremajaan pada laboratorium Komputer SMPN 101 tema yang tim kami laksanakan untuk pengabdian masyarakat ini berjalan sesuai dengan prosedur antara lain waktu dan kesediaan mitra abdimas. Pelatihan struktur maintenance dan peremajaan Komputer di SMPN 101 diawali dengan pendampingan dari guru bidang studi ke laboratorium Komputer SMPN 101, peninjauan dan melihat troubleshooting serta sistem struktur maintenance yang ada disekolah tersebut.

Kunjungan tim abdimas diawali dengan mengamati dan mengecek sistem pengkabelan dan software dari masing masing komputer tersebut dari 38 Komputer di satu laboratorium Komputer ada beberapa yang jaringannya dan software aplikasinya sudah harus di remajakan atau di upgrade, 16 Komputer lainnya berfungsi dengan baik hanya butuh maintenance di hardwarenya saja. Dilanjutkan ke ruang laboratorium ke dua dari 37 Komputer yang tim abdimas cek perangkat komputernya 10 yang membutuhkan peremajaan untuk upgrade software dan pembersihan hardwarenya, 15 komputer membutuhkan maintenance utility dan hardware banyak yang harus diganti karena sudah tidak dapat berfungsi sebagaimana mestinya , antara lain penggantian memori, keyboard, hardisk dan penginstallan serta upgrade software aplikasi selebihnya hanya pembersihan dari debu serta penggantian powersupply.

Pelatihan struktur maintenance dan peremajaan komputer sangat membantu laboratorium Komputer di SMPN 101 Jakarta Barat untuk menjaga perangkat komputer agar dapat digunakan secara kondusif dan stabil sehingga saat pelaksanaan mata pelajaran di laboratorium komputer berjalan efektif dan esisien.

Hasil yang diperoleh selama pengabdian masyarakat di SMPN 101 Jakarta Barat antara lain, Tim abdimas membuat modul manual book struktur maintenance dan peremajaan komputer untuk kedua laboratorium tersebut, baik untuk jangka waktu perawatan dan peremajaan. Dalam manual book tersebut terdapat beberapa bagian secara umum dan diperuntukan untuk laboratorium, salah satunya sistem penginstallan dapat dilakukan dengan cara Ghost untuk semua mainboard untuk mempercepat sistem instalasi komputer yang ada di laboratorium komputer SMPN 101 Jakarta Barat.

Secara umum penginstallan bisa dilakukan secara satu persatu, mulai dari pengecekan kabel, software aplikasi dan hardwarenya. Hasil lain yaitu membuat kartu pengecakan untuk tiap tiap unit komputer yang ditempatkan dibagian luar agar mudah terdeteksi tanggal awal dan kapan mulai maintenance dan peremajaan komputer tersebut. Guru guru baik yang mengajar dilaboratorium komputer menjadi lebih paham tentang struktur maintenance dan peremajaan komputer.

Evaluasi dalam kegiatan pengabdian masyarakat ini antara lain meninjau kembali dalam beberapa minggu kedepan baik dilihat secara keselurahan atau satu persatu dari perangkat input output berserta hardware dan softwarenya. Sehingga memudahkan 
pemahaman untuk para guru dan siswa /i yang menggunakan perangkat serta aplikasi komputer tersebut didalam laboratorium . Manual book serta kartu Maintenance yang ditempel dimasing masing komputer. Manual book dan kartu maintenance semoga bermanfaat untuk laboratorium komputer yang ada di SMPN 101 Jakarta Barat.

Berikut tampilan kartu maintenance dan peremajaan computer serta manual book

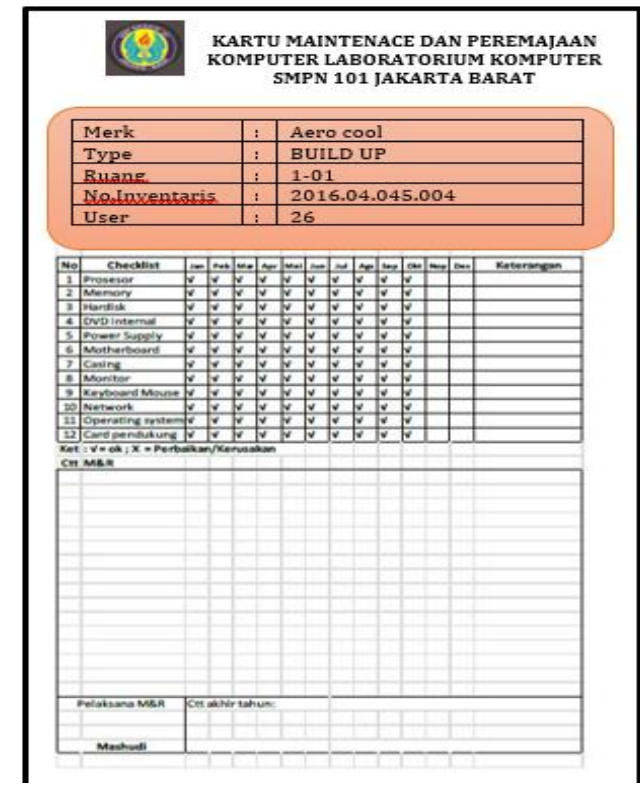

Gambar 5 Kartu Perawatan Berkala

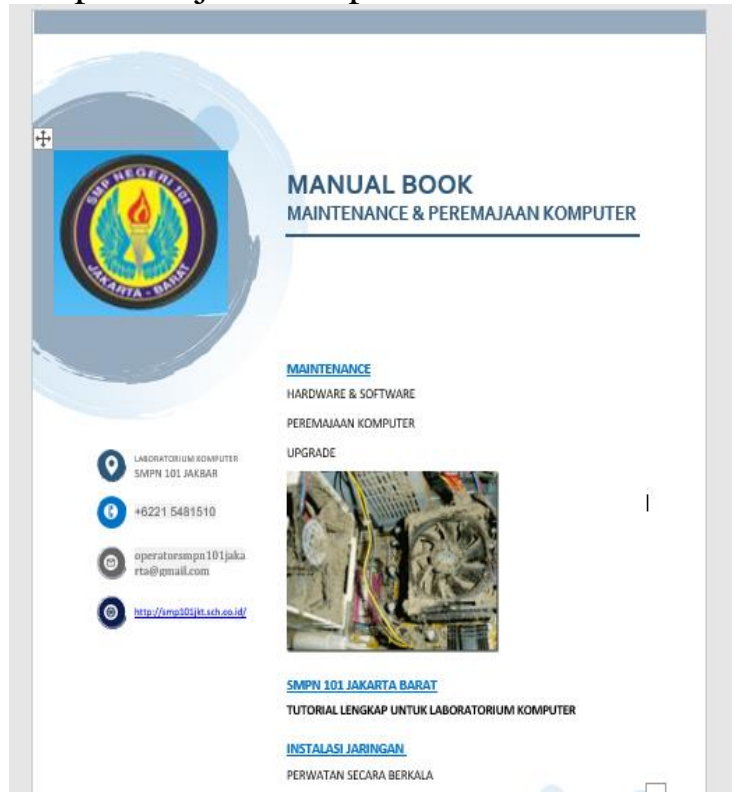

Gambar 6 Manual Book Maintenance

\section{SIMPULAN}

Simpulan dari kegiatan pengabdian masyarakat yang tim abdimas laksanakan antara lain kegiatan pengabdian masyarakat ini membantu para guru dan pihak sekolah dalam rangka menambah pemahaman tentang struktur maintenance dan peremajaan untuk laboratorium Komputer di SMPN 101 Jakarta Barat. Sehingga pemakaian dan penggunaan dapat berfungsi dengan baik saat mata pelajaran di laboratorium komputer tersebut

Adanya kegiatan pengabdian masyarakat ini di SMPN 101 Jakarta Barat, Guru dan pihak sekolah menjadi terbantu serta menambah pengetahuan tentang struktur maintenance dan peremajaan komputer.

\section{DAFTAR PUSTAKA}

Jay Heizer dan Barry Render, 2001. "Pengenalan, Permasalahan, Dan Penanganan Hardware Komputer" Andi Publisher, Jakarta

M.S Sehwarat dan J.S Narang, 2001 “Mikro Komputer” Angkasa, Yogyakarta

Permanasari, 2006 "Tip dan Trik Tingkatkan Kinerja dan Peforma Komputer" Andi Publisher, Jakarta 